Volume 1 Issue 2, July-December 2020: pp. 87-98. Indonesian Private Law Review.

Fakultas Hukum, Universitas Lampung, Bandar Lampung, Indonesia.

P-ISSN: 2723-259X E-ISSN: 2745-9284

https://jurnal.fh.unila.ac.id/index.php/iplr

\title{
KEABSAHAN TANDA TANGAN ELEKTRONIK PADA PERJANJIAN JUAL BELI BARANG DARI PERSPEKTIF HUKUM PERDATA
}

\section{AUTHORITY OF DIGITAL SIGNATURE IN AGREEMENT OF TRADING ITEMS FROM THE PERSPECTIVE OF CIVIL LAW}

\author{
Thamaroni Usman \\ Lembaga Bantuan Hukum Cinta Kasih \\ thamaroni@gmail.com
}

Submitted: August 7, 2020; Reviewed: August 25, 2020; Accepted: September 3, 2020

DOI: 10.25041/iplr.v1i2.2058

\begin{abstract}
Abstrak
Berdasarkan Pasal 1320 KUH Perdata, perjanjian akan sah ketika terpenuhinya 2 syarat, yaitu syarat subjektif dan syarat objektif. Namun disatu sisi, kesepakatan transaksi elektronik antara PT. Juang Abadi Alam dengan Australian Rural Exports Pty. Ltd yang menggunakan tanda tangan digital adalah sah dan mempunyai akibat hukum. Fokus kajian dalam tulisan ilmiah ini terkait keabsahan tanda tangan elektronik (scanner) suatu perjanjian dalam perspektif hukum perdata serta akibat hukum perjanjian yang dilakukan secara online/elektronik ketika salah satu pihak wanprestasi/cidera janji. Metode penelitian hukum yang digunakan dalam penelitian ini adalah yuridis normatif.

Hasil penelitian ini menunjukan bahwa proses terjadinya transaksi perdagangan elektronik (e-commerce) dilakukan dengan 4 tahapan teori perjanjian yaitu penawaran, penerimaan, pembayaran dan pengiriman. Keabsahan tanda tangan elektronik dalam suatu perjanjian dalam perspektif hukum perdata adalah dengan mengacu kepada hukum Informasi Transaksi Elektonik Nasional dan Peraturan Pemerintah sebagai peraturan pelaksana dari Transaksi Elektronik, yang dikaitkan dengan asas-asas perjanjian dalam KUH Perdata. Selain itu akibat hukum perikatan yang dilakukan secara online/elektronik ketika salah satu pihak wanprestasi/cidera janji adalah dapat diminta pembatalan perjanjian kepada hakim sebagai konsekuensi hukum atau akibat hukum dari wanprestasi dalam perjanjian jual beli barang secara online.
\end{abstract}

Kata Kunci: Tanda Tangan, Elektronik, Perjanjian, Jual Beli.

\begin{abstract}
Electronic transaction agreement between PT. Juang Abadi Alam with Australian Rural Exports Pty. Ltd in the perspective of the ITE Law is legal and has consequences. In another perspective, Article 1320 of the Civil Code sees that an agreement will be valid when two conditions are fulfilled, namely subjective and objective conditions. The focus of this study is related to the validity of the digital signature (scanner) of an agreement in the perspective of civil law as well as the legal consequences of the agreement carried out online / electronically when one party defaults/breach of contract. The legal research method used in this study is normative juridical.
\end{abstract}


The results of this study showed that the process of electronic commerce transactions ( $e$ commerce) is carried out with 4 stages of the agreement theory namely supply, acceptance, payment and delivery. The validity of agreement with digital signatures in the perspective of civil law is referring to the National Electronic Transaction Information law and Government Regulations as implementing regulations of Electronic Transactions, which are associated with the principles of agreement in the Civil Code. In addition, the legal consequences of an agreement made online/electronically when one of the parties to the default/breach of contract is that a cancellation of the agreement can be requested from the judge as a legal consequence or the legal consequences of the contract in the sale and purchase agreement of goods online.

Keywords: Digital, Signature, Trading, Agreement.

\section{A. Pendahuluan}

Pribadi dan organisasi, e-commerce merupakan daya tarik yang kuat dalam menjalankan bisnis. ${ }^{1}$ Menurut Laudon, E-commerce merupakan proses pembelian dan penjualan suatu produk secara elektronik yang dilakukan oleh konsumen dan perusahaan melalui computer atau gadget sebagai alat transaksi bisnis. ${ }^{2}$ Transaksi perdagangan $e$-commerce dapat muncul saat terjadinya kesepakatan perjanjian jual beli antara produsen dan konsumen yang berdasarkan hukum. ${ }^{3}$ Bahan baku utama dan yang terpenting dalam e-commerce adalah informasi. ${ }^{4}$ Apabila konsumen sepakat akan syarat-syarat dan klusula-klausula yang diajukan oleh penjual, maka terjadilah perjanjian walaupun perjanjian jual beli tersebut disepakati melalui tanda tangan yang bersifat elektronik. ${ }^{5}$

Adapun manfaat dalam penggunaan e-commerce dapat dirasakan oleh masyarakat umum, pengusaha dan konsumen. ${ }^{6}$ E-commerce memiliki berbagai keunggulan seperti lebih efisien dan efektif dalam proses jual beli karena lebih menghemat biaya dan waktu. ${ }^{7}$ Namun terdapat kekurangan dalam penerapan e-commerce yaitu pada permasalahan teknis dan nonteknologi. ${ }^{8}$ Permasalahan mulai timbul ketika transaksi dilakukan tanpa adanya tatap muka diantara kedua belah pihak. Selain faktor tersebut, transaksi jual beli secara elektronik tendesius kepada kepercayaan di antara kedua belah pihak yang saling bertransaksi. ${ }^{9}$ Masalah ini dapat terjadi yang dikarenakan didalam transaksi jual beli secara elektronik terjadi pertemuan secara langsung. Penjelasan Perundang-undangan Informasi dan Transaksi Elektronik mengatakan: "Transaksi elektronik bersifat tanpa bertatap muka (non face), tidak memakai tanda tangan asli (non sign) dan tanpa batas wilayah (seseorang dapat melakukan transaksi elektronik

\footnotetext{
1 Ambo Aco, Hutami Endang, "ANALISIS BISNIS E-COMMERCE PADA MAHASISWA UNIVERSITAS ISLAM NEGERI ALAUDDIN MAKASSAR,” Jurnal INSYPRO (Information System and Processing) 2, no. 1 (2017): 1-13, 1, DOI: 10.24252/INSYPRO.V2I1.3246.

2 Mahir Pradana, “KLASIFIKASI BISNIS E-COMMERCE DI INDONESIA,” MODUS 27, no. 2 (2016): 163-174, 163. DOI: 10.24002/modus.v27i2.554.

${ }^{3}$ Achmad Busro, Hukum Perikatan Berdasarkan Buku III KUH Perdata (Yogyakarta: Pohon Cahaya, 2011), 8.

${ }^{4}$ Edwin Agung et al., "PEMANFAATAN TEKNOLOGI E-COMMERCE DALAM PROSES BISNIS," EQUILIBIRIA 1, no. 1 (2014): 95-108, 96.

5 Agus R, Cybercrime, Pemahaman dan Upaya Pencegahan Kejahatan Berteknologi, Cet. I (Bandung: Citra Aditya Bakti, 2007), 91

6 Putra and Dimas Ernomo, "PENGARUH KEMUDAHAN TERHADAP KEMANFAATAN, MINAT DAN PENGGUNAAN E-COMMERCE (STUDI KASUS PADA PENGGUNA SITUS OLX.CO.ID)," Jurnal Administrasi Bisnis 21, no. 2 (2015): 1-8, 4.

7 Didi Achjari, "POTENSI MANFAAT DAN PROBLEM DI E-COMMERCE,"Journal of Indonesian Economy and Business 15, no. 3 (2000): 388-95, 389.

${ }^{8}$ Ahmad Firmansyah, "KAJIAN KENDALA IMPLEMENTASI E-COMMERCE DI INDONESIA," Masyarakat Telematika Dan Informasi: Jurnal Penelitian Teknologi Informasi Dan Komunikasi 8, no. 2 (2018): 127-136, 135, DOI: 10.17933/mti.v8i2.107.

9 Wika Purbasari, “MODEL KEPERCAYAAN KONSUMEN PADA SITUS E-COMMERCE,” Teknikom 1, no. 1 (2017): 39-43, 39.
} 
dengan pihak lain walaupun mereka berada di negara yang berbeda) dengan menggunakan teknologi informasi." 10

Kemajuan teknologi informasi sering kali tidak didukung dengan aspek keamanan. ${ }^{11}$ Kemajuan teknologi saat ini harus dipagari dengan berbagai aspek, seperti halnya aspek keamanan dalam informasi, jika informasi tersebut menjadi terlalu terbuka/transparan maka akan berdampak pada resiko yang harus ditanggung oleh masyarakat yang dalam konteks ini mengirim, membutuhkan, ataupun sekedar melihatnya. Selaras dengan pemanfaatan informasi elektronik tersebut memanfaatkan jaringan publik, yang mana seluruh lapisan masyarakat bisa mengetahui informasi elektronik tersebut. Apabila salah satu pihak tidak melaksanakan perjanjian dari transaksi apapun secara elektronik yang tentunya telah disepakati oleh pihak yang lain, hal ini tentu akan merugikan pihak yang berkepentingan yang dalam hal ini menggunakan teknologi informasi untuk penjualan suatu barang ataupun jasa.

Fokus kajian dalam artikel ini yaitu keabsahan tanda tangan elektronik (scanner) suatu perjanjian dalam perspektif hukum perdata serta akibat hukum perjanjian yang dilakukan secara online/elektronik ketika salah satu pihak wanprestasi/cidera janji. Metode penelitian hukum yang akan dipakai dalam artikel ini adalah yuridis normative. Penelitian yuridis normatif merupakan penelitian yang bersifat teoritis terkait konsep, doktrin, asas, dan peraturan hukum yang berhubungan dengan penelitian ini. ${ }^{12}$ Penelitian ini menggunakan pendekatan perundang-undangan (state approach), pendekatan kasus (case approach), pendekatan historis (historical approach), pendekatan komperatif (comperative approach) dan pendekatan konseptual (conceptual approach).

\section{B. Pembahasan}

\section{Proses Terjadinya Transaksi Perdagangan Elektronik (E-commerce)}

Penggunaan internet dipilih oleh kebanyakan pelaku usaha dan konsumen dikarenakan kemudahan-kemudahan yang disediakan oleh jaringan internet, seperti mempermudah pekerjaan dalam mendapatkan informasi dengan cepat. ${ }^{13}$ Pada dasarnya manfaat dari mengakses internet adalah adanya kemudahan dalam pencarian informasi, baik terkait kehidupan pribadi, maupun terkait informasi professional pekerjaan. ${ }^{14}$ Terdapat 3 (tiga) tahapan dalam pelaksanaan transaksi e-commerce yaitu sebagai berikut: ${ }^{15}$

a. Tahap Pra Kontraktual dalam Pelaksanaan Transaksi Jual Beli E-Commerce.

b. Tahap Kontraktual dalam Pelaksanaan Transaksi Jual Beli E-Commerce.

c. Tahap Post Kontraktual dalam Pelaksanaan Transaksi Jual Beli E-Commerce.

Selaras dengan penjabaran tersebut di atas dalam mekanismenya, penulis mendeskripsikan transaksi perdagangan yang dibuat secara eletkronik antara PT. Juang

\footnotetext{
${ }^{10}$ Dini Sukma Listyana, Ismi Ambar Wati, Lisnawati, "Kekuatan Pembuktian Tanda Tangan Elektronik Sebagai Alat Bukti Yang Sah Dalam Perspektif Hukum Acara Di Indonesia dan Belanda," Jurnal Verstek 2, no. 2 (2014): 146-154, 147.

${ }^{11}$ Herny Februariyanti, "Standar Dan Manajemen Keamanan Komputer," Jurnal Teknologi Informasi DINAMIK 11, no. 2 (2006): 134-42, 134.

12 Andriawan Kusuma et al., "GANTI RUGI TANAH SISA PADA PEMBANGUNAN JALAN TOL BAKAUHENITERBANGGI BESAR; AKIBAT HUKUM DAN KONFLIK PERTANAHAN (COMPENSATION FOR REMAINING LAND IN THE CONSTRUCTION OF THE BAKAUHENI-TERBANGGI BESAR TOLL ROAD; DUE TO LAWS AND LAND CONFLICTS)," Cepalo 3, no. 1 (2019): 41-54, 43, DOI: 10.25041/cepalo.v3no1.1785.

13 Zainuri and Achmat, "PENGARUH KEMUDAHAN PENGGUNAAN DAN KEMANFAATAN TEKNOLOGI INFORMASI BERBASIS WIRELESS TERHADAP NIAT PENGGUNA INTERNET (Studi Pada Pengguna Akses Indonesia Wifi (Wifi.Id) PT. Telekomunikasi Indonesia, Tbk. Kandatel Lamongan),” Jurnal Administrasi Bisnis 27, no. 1 (2015): 1-9, hlm. 2.

${ }^{14}$ Made Rendy Wicaksana Adiutama, I Wayan Santika, "PENGARUH PERSEPSI KEMUDAHAN PENGGUNAAN, KEGUNAAN YANG DIRASAKAN DAN TINGKAT PENDIDIKAN TERHADAP NIAT BERBELANJA KEMBALI PADA SITUS TOKOBAGUS.COM", E-Jurnal Manajemen 3, no. 10 (2014): 2815-2832, 2816.

$15 \mathrm{Ni}$ Nyoman Ernita Ratnadewi, "PELAKSANAAN TRANSAKSI E-COMMERCE BERDASARKAN UNDANGUNDANG NOMOR 11 TAHUN 2008”, Jurnal IuS 2, no. 5 (2014): 385-395, 394.
} 
Jaya Abdi Alam, yang berdomisili di Desa Sukabanjar, Kecamatan Sidomulyo, Kabupaten Lampung, Selatan, Indonesia selaku Pembeli dengan Australian Rural Exports Pty. Ltd, yang berdomisili di Level 8, 10 Eagle Street, Brisbane QLD 4000, Australia. Sebagai berikut:

\section{Gambar 1}

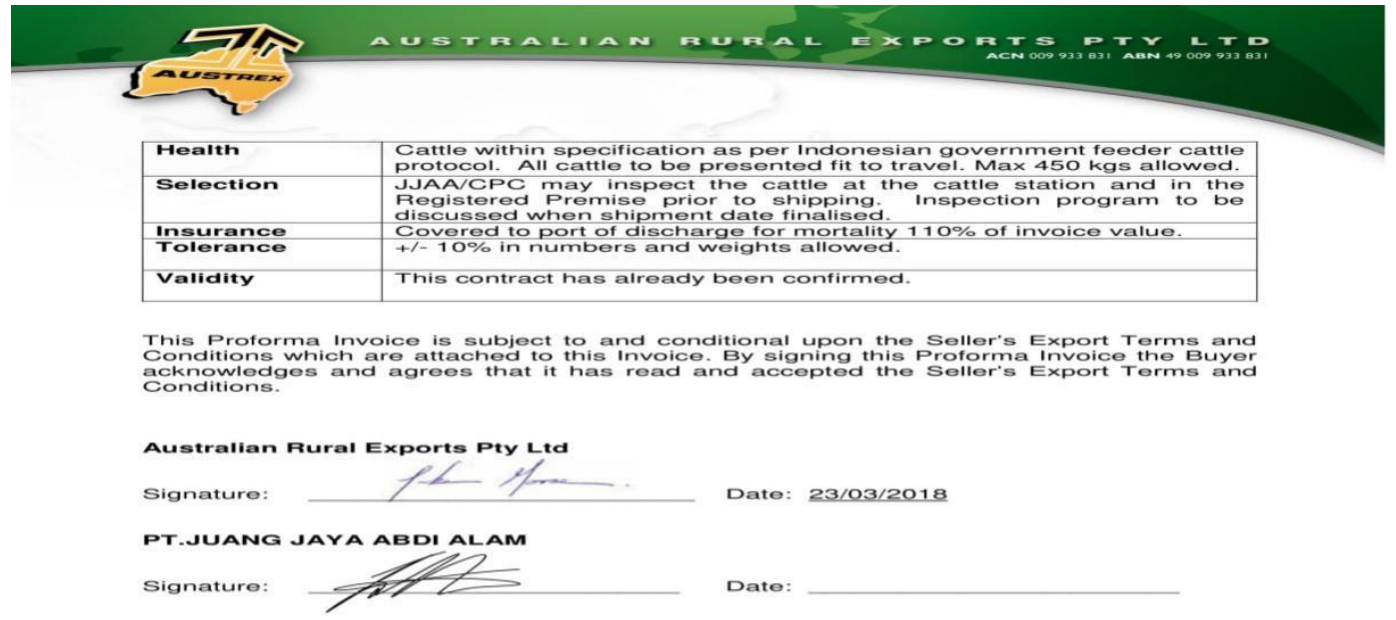

Perjanjian e-commerce yang telah disepakati oleh PT. Juang Abadi Alam dengan Australian Rural Exports Pty. Ltd tertuang di atas, maka keuntungan dan kerugian yang dapat diperoleh bagi kedua belah pihak adalah sebagai berikut: ${ }^{16}$

a. Keuntungan:

1) Untuk sebuah perusahaan, dapat meringkas jarak, memperluas pasar, memperluas jeringan mitra usaha dan efektivitas, sederhananya akan mempercepat pelayanan suatu perusahaan kepada seluruh pelanggan, serta pelayanan akan menjadi lebih responsif, dan tentunya akan juga mengurangi operasional yang berhubungan dengan kertas, layaknya seperti anggaran surat pos, percetakan, laporan, dan lainnya, sehingga akan berdampak positif kepada meningkatnya pendapatan.

2) Terhadap Konsumen, tentunya akan menimbulkan dampak yang lebih efektif, aman secara nyata.

b. Kerugian:

Mengurangnya solidaritas dalam berdagang, pada perdagangan dengan pemanfaatan elektronik masyarakat dapat bertransaksi serta meraih barang yang diperlukan tanpa bertemu dengan pihak lainnya. Walaupun kadang kala memicu kekesalan, sesuatu yang dilihat di layar pengiklanan lain hal nya dengan apa yang ditinjau secara langsung.

\section{Keabsahan Tanda Tangan Elektronik Suatu Perjanjian dalam Perspektif Hukum Perdata}

Seiring dengan perkembangan zaman, maka berdampak pula pada perkembangan praktek perdagangan, seperti adanya penggunaan tandatangan elektronik dalam suatu perjanjian. ${ }^{17}$

\footnotetext{
${ }^{16}$ Wawancara penulis dengan Zul Armain selaku Advokat, wawancara pada tanggal 16 Mei 2019.

17 Putri Visky Saruji dan Nyoman A. Martana, "KEKUATAN HUKUM PEMBUKTIAN TANDATANGAN PADA DOKUMEN ELEKTRONIK SEBAGAI ALAT BUKTI DALAM HUKUM ACARA PERDATA", Kertha Semaya: Journal Ilmu Hukum 4, no. 2 (2016): 1-5, 2.
} 
Tanda tangan elektronik dibuat menggunakan teknik cryptography, dan public key cryptography dan diperoleh melalui transaksi perjanjian terlebih dahulu, hal ini berdasar pada Pasal 1320 KUHPerdata. ${ }^{18}$ Sebagaimana yang diatur dalam Undang-Undang No. 11 Tahun 2008 tentang Informasi dan Transaksi Elektronik (selanjutnya disebut dengan UU ITE) dan Peraturan Pemerintah Nomor 82 Tahun 2012 tentang Penyelenggaraan Sistem dan Transaksi Elektronik (selanjutnya disebut dengan PP PSTE), terdapat syarat agar tanda tangan elektronik secara sah diakui oleh hukum di Indonesia, yaitu adanya keaslian (authentication), keutuhan (integrity), dan nirsangkal (non-repudiation). ${ }^{19}$

Tanda tangan digital dalam transaksi bisnis yang dilakukan antara PT. Juang Abadi Alam dengan Australian Rural Exports Pty. Ltd dikonsepkan dengan memakai gagasan teknik kriptografi, yang merupakan satu bagian dari matematik terapan yang dalam konteks ini mengatasi perubahan informasi jadi model lain yang tak bisa dipahami dan dikembalikan seperti awal. Penandatanganan digital memanfaatkan kriptografi kunci publik, yang mana algoritma menggunakan 2 kunci, yang ke-satu adalah kunci agar membuat tanda tangan digital atau seperti mengganti data ke wujud lain yang dalam hal ini tidak bisa dipahami. Selanjutnya kunci ke-dua dimanfaatkan untuk memverifikasi tanda tangan digital atau pengembalian pesan kedalam wujud awal. Konsep itupun dapat diingat sebagai sistem kriptografi non simetris. ${ }^{20}$

Model sistem kriptografi ini memakai kunci rahasia, tetapi hanya akan diingat oleh penandatangan serta dimanfaatkan untuk membuat tanda tangan digital, publik kunci, ini digunakan untuk memverifikasi tanda tangan digital. Ketika sebagian orang akan memverifikasi suatu tanda tangan digital yang dikeluarkan oleh orang, lalu kemudian kunci publik itu wajib disebarluaskan kepada orang-orang itu. Kunci privat dan kunci publik tersebut sebetulnya telah secara matematis saling bertautan. Walaupun kunci privat tak bisa diketahui dengan penggunaan informasi yang diperoleh dari kunci publik. Tanda tangan digital antara PT. Juang Abadi Alam dengan Australian Rural Exports Pty. Ltd adalah salah satu cara agar menjamin kelegalan dokumen elektronik serta dapat menjaga agar pengirim dokumen pada suatu ketika tak bisa menyanggah bahwa dia sudah mengirim dokumen tersebut. Penandatanganan secara digital memakai algoritma dan teknik komputer yang khusus pada terapannya. ${ }^{21}$

Penggunaan tanda tangan digital yang dilakukan antara PT. Juang Abadi Alam dengan Australian Rural Exports Pty. Ltd memerlukan 2 langkah proses, yaitu dari subjek penandatangan dan serta dari pihak penerimanya. Secara rinci ke-dua proses ini dapat dijelaskan seperti berikut ini: ${ }^{22}$

a. Pembuatan kepada tanda tangan digital memanfaatkan nilai hash yang diperoleh dari file dan kunci privat yang sudah diartikan sebelumnya. Guna mengunci keamanan terhadap nilai hash maka kemudian harus memuat kemungkinan yang sedikit bahwa tanda tangan digital yang sama dapat diperoleh dari 2 (dua) dokumen serta kunci privat yang tidak sama.

b. Verifikasi terhadap tanda tangan digital merupakan proses validasi tanda tangan digital dengan cara mengacu pada dokumen asli serta kunci publik yang sudah diberi, langkah tersebut bisa disimpulkan apa tanda tangan digital disetting untuk

\footnotetext{
${ }^{18}$ Husnul Hudzaifah, "KEABSAHAN TANDA TANGAN ELEKTRONIK DALAM PEMBUKTIAN HUKUM ACARA PERDATA INDONESIA,” Katalogis 3, no. 5 (2015): 194-204, 196.

${ }^{19}$ Affan Muhammad Andalan, "KEDUDUKAN TANDA TANGAN ELEKTRONIK DALAM TRANSAKSI TEKNOLOGI FINANSIAL," Jurist-Diction 2, no. 6 (2019): 1931-1950, 1948, DOI: 10.20473/jd.v2i6.15921.

${ }^{20}$ Egi Cahyo Prabowo and Irawan Afrianto, "PENERAPAN DIGITAL SIGNATURE DAN KRIPTOGRAFI PADA OTENTIKASI SERTIFIKAT TANAH DIGITAL,” Komputa : Jurnal Ilmiah Komputer Dan Informatika 6, no. 2 (2017): 8390, 84, DOI: 10.34010/komputa.v6i2.2481.

${ }^{21}$ Wawancara penulis dengan Zul Armain selaku Advokat, wawancara pada tanggal 16 Mei 2019.

${ }^{22}$ Wawancara penulis dengan Zul Armain selaku Advokat, wawancara pada tanggal 16 Mei 2019.
} 
dokumen yang sama dengan memakai kunci privat yang tendesius dengan kunci publik.

Dalam hal penandatanganan sebuah dokumen antara PT. Juang Abadi Alam dengan Australian Rural Exports Pty. Ltd, dalam implikasi tanda tangan, hal yang utama adalah dibatasi dengan komprehensif bagian mana yang akan ditandatangani. Informasi telah dipisahkan tersebut disebut sebagai pesan. Selanjutnya aplikasi tanda tangan digital akan membuat suatu nilai hash yang jadi tanda tangan digital dengan mengacu pada privat key. Pada dasarnya terhadap sebuah tanda tangan elektronik tersebut disertakan pada dokumennya.

Bagaimanapun juga, tanda tangan digital dapat dikirimkan serta disimpan sebagai dokumen yang dibedakan, semasa masih bisa di khususkan dengan dokumen tersebut, hal tersebut dapat terjadi dikarenakan tanda tangan digital bersifat khas pada dokumennya, sehingga pemisahan pada tanda tangan digital seperti penjabaran tersebut diatas adalah hal yang tidak perlu diaplikasikan. Metode pembentukan serta memverifikasikan tanda tangan digital harus terpenuhinya unsur substansial penting yang diminta pada suatu tujuan hukum, yaitu sebagai berikut: ${ }^{23}$

a. Otentisitas Penandatangan Dokumen. Ketika pasangan kunci publik serta kunci privat bermitra dengan pemilik yang sah dan telah di tafsirkan, maka tanda tangan digital akan menghubungkan ke dokumen dengan penandatangan tersebut. selanjutnya tanda tangan digital tersbut tidak akan dapat dipalsukan, kecuali dalam hal penandatangan kehilangan kontrol dari kunci privat.

b. Otentisitas Dokumen. Tanda tangan digital dapat juga mengidentikkan dokumen yang telah ditandatangani pada tingkat kepastian dan akurasi yang jauh lebih tinggi dari tanda tangan di atas kertas pada umumnya.

c. Pengesahan Dokumen. Menciptakan tanda tangan digital membutuhkan pemanfaatan kunci privat dari penandatangan tersebut. Metode tersebut bisa juga menekankan bahwa penandatangan merupakan persetujuan sera pertanggung jawaban dokumen.

d. Efisiensi. Mekanisme dalam pembuatan verifikasi terhadap tanda tangan digital menyajikan ambang kejelasan yang tinggi, bahwa kemudian tanda tangan yang tersaji adalah tanda tangan yang sah serta bahkan asli dari pemilik kunci privat. Tanda tangan digital, tak harus ada verifikasi dengan meninjau dengan jelas (membandingkan) antara tanda tangan yang ada di dokumen dengan contoh tanda tangan asli yang bisa dilakukan pada validasi tanda tangan secara manual.

Sehubungan dengan syarat sahnya kontrak bisnis secara elektronik yang dilakukan antara PT. Juang Abadi Alam dengan Australian Rural Exports Pty. Ltd, berdsarkan pada ketentuan Pasal 1320 KUH Perdata sebetulnya tidak mempermasalahkan perkara media yang difungsikan pada transaksi, atau dengan kata lain Pasal $1320 \mathrm{KUH}$ Perdata tidak mewajibkan bentuk serta jenis media yang digunakan dalam bertransaksi. Oleh sebab itu, bisa saja melakukan dengan langsung maupun secara elektronik. Namun suatu perjanjian dapat dikatakan sah bila telah memenuhi unsur-unsur sebagaimana dimaksud dalam Pasal 1320 tersebut.

\section{Akibat Hukum Perjanjian Yang Dilakukan secara Online Ketika Salah Satu Pihak Wanprestasi}

Kegiatan transaksi jual beli yang dilakukan dengan metode elektronik oleh pihak terkait, ketika para pihak tidak bertemu atau tidak saling tatap muka, tapi hal tersebut dapat diimplementasikan melalui internet. Pada umumnya setiap golongan pada konteks jual beli yang dilakukan secara elektronik itu, tetap mempunyai hak serta kewajiban, sama seperti transaksi yang dilakukan secara langsung. Bahwa penjual merupakan pihak yang menawarkan

\footnotetext{
${ }^{23}$ Wawancara penulis dengan Zul Armain selaku Advokat, wawancara pada tanggal 20 Mei 2019.
} 
produk, hanya saja fasilitas yang digunakan dengan internet, oleh sebab hal tersebut penjual wajib bertanggung jawab memberi secara benar serta jujur terhadap produk yang presentasikan kepada konsumen dan penjual pun harus menjual produk yang tak menyimpang dari peraturan perundang-undangan yang ada di Indonesia. Maksudnya adalah barang yang ditawarkan, bukanlah barang yang dilarang untuk diperjual belikan, seperti organ tubuh dan narkotika, tidak cacat, sehingga barang yang ditawarkan adalah barang yang layak untuk di konsumsi atau di manfaatkan.

Selain itu, penjual pun bertanggung jawab terhadap jasa pengiriman produk atau atas jasa yang telah dibeli dan dibayarkan oleh konsumen. Sehingga transaksi jual beli tersebut tidak berdampak kepada timbulnya kerugian bagi para pihak, khsusnya dalam hal ini adalah konsumen. Sejalan dengan hal tersebut, salah satu penjual ataupun pelaku usaha mempunyai hak agar mendapat bayaran dari pembeli atau konsumen dari kesepakatan harga barang yang dijual serta berhak mendapatkan pengamanan dari perlakuan pembeli yang berniat tidak baik dalam melakukan transaksi jual beli online. Oleh karna itu, pembeli wajib untuk memberikan sejumlah uang dari produk atau jasa yang telah dipesan pada penjual itu.

Pembeli mempunyai kewajiban membayar uang dari barang yang telah dipesan dari penjual sesuai dengan jenis barang dan harga yang telah diberitahukan oleh penjual kepada pembeli itu, selanjutnya menulis data identitas diri dengan benar pada formulir penerimaan. Selain itu, seorang pembeli juga berhak mendapatkan informasi dengan lengkap dari barang yang akan dibeli. Pembeli pun mempunyai hak mendapatkan perlindungan hukum dari perbuatan penjual atau pelaku usaha yang berniat tidak baik.

Proses jual beli secara online adalah hubungan hukum yang dilakukan dengan menyatukan jaringan dari sistem dan informasi. Pada suatu pekerjaan timbal balik pasti terdapat dua macam subjek hukum, yang setiap subjek hukum itu memiliki hak juga kewajiban dengan timbal balik pada perjanjian yang telah mereka buat. Perjanjian jual beli adalah suatu perjanjian bertimbal balik, kedua subjek hukumnya itu pihak konsumen dan pedagang yang masing-masing memiliki hak serta kewajiban. Dalam seluruh perjanjian, yang masuk dalam kategori perjanjian jual beli terdapat kemungkinan diantara satu pihak tak melakukan perjanjian ataupun tidak mematuhi isi dari perjanjian secara baik dan benar.

Apabila salah satu pihak tidak melakukan sesuatu yang telah dijanjikan atau lebih jelas, apa yang menjadi kewajiban menurut isi perjanjian yang telah mereka perbuat, mereka dapat dikatakan bahwa pihak tersebut telah melakukan wanprestasi. ${ }^{24}$ Wanprestasi adalah tidak memenuhi atau lalainya suatu prestasi dalam hukum perjanjian, berarti suatu hal harus dilaksanakan sebagai isi dari suatu perjanjian. ${ }^{25}$ Barangkali dalam bahasa indonesia dapat dipakai istilah pelaksanaan janji untuk wanprestasi. Apabila dalam suatu perikatan si debitur yang disebabkan oleh kesalahannya, seperti tidak melaksanakan apa yang telah diperjanjikan dan disepakati, maka perbuatan tersebut merupakan perbuatan wanprestasi. ${ }^{26}$

Selain mengaitkan pihak penjual dan pembeli, dalam konteks jual beli yang dengan menggunakan sarana internet, transaksi jual beli online juga tentunya akan melibatkan provider internet sebagai penyedia fasilitas layanan jaringan internet, serta wadah perbankan sebagai sarana dalam metode pembayarannya. Problematika terhadap hak dan kewajiban pedagang/penjual sebagai pelaku usaha dan pembeli sebagai konsumen terkadang membuat masyarakat abu-abu dalam menyikapi, apalagi jika terjadi perselisihan antara keduanya, khsususnya dalam jual beli yang dilakukan secara online, seperti perbuatan wanprestasi dalam jual beli.

Betolak belakang dari penjelasan tersebut diatas, seringkali dijumpai oleh seluruh lapisan

\footnotetext{
${ }^{24}$ Wirjono. P, Hukum Perdata Tentang Persetujuan-Persetujuan Tertentu (Bandung, Sumur Bandung, 1991), 17.

25 A. A. Pradnyaswari, "UPAYA HUKUM PENYELESAIAN WANPRESTASI DALAM PERJANJIAN SEWA MENYEWA KENDARAAN (RENT A CAR)", Jurnal Advokasi 3, no. 3 (2013): 119-130, hlm. 126.

${ }^{26}$ H. Mariam Darus Badrulzaman, Hukum Perdata Tentang Perikatan (Medan: Fakultas Hukum USU, 1994), 33
} 
masyarakat, dalam era globaliasi terakait maraknya kasus perselisihan yang identik dengan wanprestasi, sampai pada persoalan yang tendesius pada penipuan dalam transaksi jual beli dengan media elektronik sampai saat ini tidak dapat terselsaikan secara komprehensif. Kesenjangan dapat disebabkan oleh karena sikap dalam menghadapi suatu persoalan ole para pihak, padahal masih banyak alternatif cara untuk dapat menyelesaikan persoalan wanprestasi. Dalam hal telah terjadi perbuatan wanprestasi, maka salah satu pihak yang dalam hal ini menderita kerugian bisa memilih pilihan-pilihan hukum sebagai berikut dalam penyelesainnya, yaitu sebagai berikut:

a. Seorang yang telah di rugikan dapat menggugat agar perjanjian tersebut segara dilaksanakan sesuai dengan apa yang diperjanjikan;

b. Seorang yang telah di rugikan dapat menggugat ganti kerugian;

c. Seorang yang telah di rugikan dapat menggugat praktik perjanjian serta mengganti kerugian;

d. Seorang yang telah di rugikan dapat menggugat pembatalan perjanjian;

e. Seorang yang telah di rugikan dapat menggugat pembatalan perjanjian disertai ganti rugi.

Berdasarkan penjelasan tersebut penulis menganalisis bahwa:

a. Pihak yang telah dirugikan dapat menuntut pelaksanaan perjanjian tersebut segara dilaksanakan sesuai dengan apa yang diperjanjikan. Dalam konteks kesepakatan jual beli elektronik yang disetujui dengan tanda tangan elektronik dan menggunakan metode bayar serta melunasi serta memenuhi secara utuh dan penuh pada batas waktu yang telah ditentukan konsumen, kemudian penjual mengirimkan barang yang sudah disepakati, tetapi kemudian ketika pembeli sudah melaksanakan kelebihannya tapi penjual tak melaksanakan kelebihannya secara akurat, maka pembeli bisa menggugat atas dilakukannya kesepakatan jual beli secara utuh kepada penjual.

b. Pihak yang telah di rugikan dapat menggugat untuk mengganti kerugian. Suatu kesepakatan jual beli elektronik bisa disetujui bahwa pembayaran akan dilunasi secara penuh terlebih dahulu, kemudian penjual baru akan mengirimkan barang yang sudah disetujui oleh konsumen, tetapi dalam kenyataan, biasanya barang yang telah dikirimkan tersebut mendapati cacat hingga berrkurangnya nilai guna / nilai jual atas barang itu, kemudian pihak konsumen bisa mengugat untuk mengganti rugi pada penjual, biasanya seperti dengan apa yang telah disepakati.

c. Pihak yang telah di rugikan dapat menggugat pelaku perjanjian serta mengganti kerugian.

Dalam kesepakatan jual beli elektronik, tentunya telah disetujui bahwa pembayaran wajib melunasi terlebih dulu secara penuh dan selanjutnya penjual akan mengirimkan barang yang sudah disetujui tersebut. Tetapi problem yang terjadi, barang yang sudah dikirimkan telat waktu serta barang tersebut tak seperti dengan apa yang telah disetujui oleh para pihak, misalkan; bentuk, warna, model ukuran. Hingga berdampak kepada tuntutan pembeli dalam melakukan perjanjian secara peuh dan mengganti kerugian seperti dengan persetujuan keduanya.

a. Pihak yang telah di rugikan dapat menggugat membatalkan kesepakatan. Pada suatu kesepakatan jual beli elektronik, misalkan disetujui terhadap pembayaran 15\% terlebih dahulu lalu selanjtnya harus melunasi setelahnya, selanjutnya barang dikirimkan oleh penjual. Tetapi kemudian yang terjadi adalah si pembeli belum juga melunasi pembayaran terhadap barang itu pada jangka waktu yang telah disepakati. Sehingga penjual bisa juga melakukan penuntutan terhadap pembatalan perjanjian.

b. Pihak yang telah di rugikan dapat mengugat pembatalan kesepakatan serta mengganti kerugian. Pada suatu kesepakatan jual beli elektronik, disetujui bahwa dalam hal pembayaran harus melunasi secara penuh dalam jangka waktu yang telah disepakati, lalu penjual mengirimkan barang yang telah disetujui tersebut oleh konsumen, tetapi yang 
menjadi problem adalah ketika si pembeli telah melakukan pembayaran tetapi si penjual belum juga mengirimkan barang tersebut, sehingga pembeli dapat menggugat pembatalan kesepakatan serta mengganti kerugian.

Sejalan dengan hasil analisis tersebut diatas, bahwa beberapa kemungkinan gugatan dari salah satu yang mengalami kerugian tersebut pada suatu kesepakatan timbal balik yang ditentukan oleh pasal $1266 \mathrm{KUH}$ Pdt dengan syarat jika salah satu pihak tak melakukan kewajibannya bisa dilakukan pembatalan kesepakatan pada hakim sebagai konsekuensi hukum atau akibat hukum dari wanprestasi dalam perjanjian jual beli barang secara online. Dengan demikian berdasarkan kitab hukum perdata, tepatnya pada pasal 1266, menegaskan bahwa pada kesepakatan jual beli apabila salah satu pihak wanprestasi maka pihak yang mengalami kerugian bisa memelalui upaya hukum untuk menggugat pembatalan kesepakatan pada hakim. Pada realitanya dalam kesepakatan jual beli muncul persoalan antara kedua belah pihak, para pihak terjerat pada apa yang telah disepakati kedua belah pihak.

\section{Kesimpulan}

Keabsahan suatu perikatan yang dilakukan dengan menggunakan tanda tangan elektronik dalam perspektif hukum perdata adalah berdasarkan pada asas-asas perjanjian sebagaimana yang termuat dalam KUH Perdata, kemudian dikaitkan dengan Undang-Undang Nomor 19 Tahun 2016 perubahan atas Undang-Undang Nomor 11 Tahun 2008 tentang Informasi Transaksi Elektonik dan Peraturan Pemerintah Nomor 82 Tahun 2012 tentang Transaksi Elektronik. Selanjutnya terkait sejauh mana keabsahan tanda tangan elektronik jual beli barang online dalam perspektif hukum pembuktian adalah jika kontrak jual beli yang terjadi secara elektronik dapat dikatakan sah, maka kontrak tersebut juga harus memenuhi persyaratan sahnya perjanjian menurut Pasal 1320 KUH Perdata tersebut.

Akibat hukum perikatan yang dilakukan secara online/elektronik ketika salah satu pihak wanprestasi/cidera janji adalah dapat diminta pembatalan perjanjian kepada hakim sebagai konsekuensi hukum atau akibat hukum dari wanprestasi dalam perjanjian jual beli barang secara online. Oleh karna itu berdasarkan pasal 1266 KUH Perdata, pada kesepakatan jual beli salah satu pihak wanprestasi maka pihak yang mengalami kerugian dapat melalui jalur hukum dengan menggugat pembatalan kesepakatan pada hakim. Namun realitanya dalam wujud kesepakatan jual beli sering muncul permasalahan antara keduabelah pihak, oleh karna itu pihak yang terjerat dalam isi kesepakatan yang telah disepakati keduanya itu dengan menyelesaikan permasalahan dengan cara musyawarah, atau di lakukan via pengadilan dimana kesepakatan Proses menyelesaikan lewat jalur pengadilan atau meja hijau itu pilihan terakhir. 


\section{DAFTAR PUSTAKA}

\section{A. Jurnal}

Achjari, Didi. "POTENSI MANFAAT DAN PROBLEM DI E-COMMERCE," Journal of Indonesian Economy and Business 15, no. 3, 2000: 388-95.

Aco, Ambo., Endang, Hutami. "ANALISIS BISNIS E-COMMERCE PADA MAHASISWA UNIVERSITAS ISLAM NEGERI ALAUDDIN MAKASSAR," Jurnal INSYPRO (Information System and Processing) 2, no. 1, 2017: 1-13, DOI: 10.24252/INSYPRO.V2I1.3246.

Adiutama, Made Rendy Wicaksana., Santika, I Wayan. "PENGARUH PERSEPSI KEMUDAHAN PENGGUNAAN, KEGUNAAN YANG DIRASAKAN DAN TINGKAT PENDIDIKAN TERHADAP NIAT BERBELANJA KEMBALI PADA SITUS TOKOBAGUS.COM", E-Jurnal Manajemen 3, no. 10, 2014: 2815-2832.

Agung, Edwin et al. "PEMANFAATAN TEKNOLOGI E-COMMERCE DALAM PROSES BISNIS," EQUILIBIRIA 1, no. 1, 2014: 95-108.

Andalan, Affan Muhammad. "KEDUDUKAN TANDA TANGAN ELEKTRONIK DALAM TRANSAKSI TEKNOLOGI FINANSIAL.” Jurist-Diction 2, no. 6, 2019: 1931-1950, DOI: $10.20473 /$ jd.v2i6.15921.

Februariyanti, Herny. "STANDAR DAN MANAJEMEN KEAMANAN KOMPUTER," Jurnal Teknologi Informasi DINAMIK 9, no. 2, 2006: 134-142.

Firmansyah, Ahmad. "KAJIAN KENDALA IMPLEMENTASI E-COMMERCE DI INDONESIA," Masyarakat Telematika Dan Informasi: Jurnal Penelitian Teknologi Informasi Dan Komunikasi 8, no. 2, 2018: 127-136, DOI: 10.17933/mti.v8i2.107.

Hudzaifah, Husnul. "KEABSAHAN TANDA TANGAN ELEKTRONIK DALAM PEMBUKTIAN HUKUM ACARA PERDATA INDONESIA," Katalogis 3, no. 5, 2015: 194-204.

Kusuma, Andriawan et al. "GANTI RUGI TANAH SISA PADA PEMBANGUNAN JALAN TOL BAKAUHENI-TERBANGGI BESAR; AKIBAT HUKUM DAN KONFLIK PERTANAHAN (COMPENSATION FOR REMAINING LAND IN THE CONSTRUCTION OF THE BAKAUHENI-TERBANGGI BESAR TOLL ROAD; DUE TO LAWS AND LAND CONFLICTS)." Cepalo 3, no. 1, 2019: 41-54, DOI: 10.25041/cepalo.v3no1.1785.

Listyana, Dini Sukma., Wati, Ismi Ambar., Lisnawati. "KEKUATAN PEMBUKTIAN TANDA TANGAN ELEKTRONIK SEBAGAI ALAT BUKTI YANG SAH DALAM PERSPEKTIF HUKUM ACARA DI INDONESIA DAN BELANDA." Jurnal Verstek 2, no. 2, 2014: 146-154.

Prabowo, Egi Cahyo., Afrianto, Irawan. "PENERAPAN DIGITAL SIGNATURE DAN KRIPTOGRAFI PADA OTENTIKASI SERTIFIKAT TANAH DIGITAL," Komputa: Jurnal Ilmiah Komputer Dan Informatika 6, no. 2, 2017: 83-90, DOI: 10.34010/komputa.v6i2.2481.

Pradana, Mahir. "KLASIFIKASI BISNIS E-COMMERCE DI INDONESIA," MODUS 27, no. 2, 2016: 163-174, DOI: 10.24002/modus.v27i2.554.

Pradnyaswari, A. A. "UPAYA HUKUM PENYELESAIAN WANPRESTASI DALAM PERJANJIAN SEWA MENYEWA KENDARAAN (RENT A CAR)", Jurnal Advokasi 3, no. 3, 2013: 119-130.

Purbasari, Wika. "MODEL KEPERCAYAAN KONSUMEN PADA SITUS ECOMMERCE." Teknikom 1, no. 1, 2017: 39-43.

Putra., Ernomo, Dimas. "PENGARUH KEMUDAHAN TERHADAP KEMANFAATAN, MINAT DAN PENGGUNAAN E-COMMERCE (STUDI KASUS PADA PENGGUNA SITUS OLX.CO.ID)," Jurnal Administrasi Bisnis 21, no. 2, 2015: 1-8. 
Ratnadewi, Ni Nyoman Ernita. "PELAKSANAAN TRANSAKSI E-COMMERCE BERDASARKAN UNDANG-UNDANG NOMOR 11 TAHUN 2008". Jurnal IuS 2, no. 5, 2014: 385-395.

Saruji, Putri Visky., Martana, Nyoman A. "KEKUATAN HUKUM PEMBUKTIAN TANDATANGAN PADA DOKUMEN ELEKTRONIK SEBAGAI ALAT BUKTI DALAM HUKUM ACARA PERDATA", Kertha Semaya : Journal Ilmu Hukum 4, no. 2, 2016: 1-5.

Zainuri., Achmat. "PENGARUH KEMUDAHAN PENGGUNAAN DAN KEMANFAATAN TEKNOLOGI INFORMASI BERBASIS WIRELESS TERHADAP NIAT PENGGUNA INTERNET (STUDI PADA PENGGUNA AKSES INDONESIA WIFI (WIFI.ID) PT. TELEKOMUNIKASI INDONESIA, TBK. KANDATEL LAMONGAN)," Jurnal Administrasi Bisnis 27, no. 1, 2015: 1-9.

\section{B. Buku}

Badrulzaman, Mariam Darus. Kompilasi Hukum Perikatan. Bandung: Citra Aditya Bakti, 2001.

Budiono, Herlien. Ajaran Umum Hukum Perjanjian dan Penerapannya di Bidang Kenotariatan. Bandung: Citra Aditya Bakti, 2012.

Budiono, Herlien. Kumpulan Tulisan Hukum Perdata Di Bidang Kenotariatan. Bandung: Citra Aditya Bakti, 2007.

Busro, Ahmad. Hukum Perikatan Berdasarkan Buku III KUH Perdata. Yogyakarta: Pohon Cahaya, 2011.

Hanafiah, Ali. Kesiapan Infrastruktur dan Sistem Antaran Tepat Waktu dalam Mendukung electronic-Commerce, dalam Seminar E-Commerce Revolusi Teknologi Informasi dan Pengaruhnya pada Peta Perdagangan Global. Bandung, 2014.

Miru, Ahmadi. Hukum Kontrak Perancangan Kontrak. Jakarta: Raja Grafindo Persada, 2007.

Nugroho, Adi. E-Commerce Memahami Perdagangan Modern Di Dunia Maya. Bandung: Informatika, 2006.

Partodihardjo, Soemarno. Tanya Jawab Sekitar Undang-Undang No.11 Tahun 2008 tentang Informasi dan Transaksi Elektronik. Jakarta: Gramedia Pustaka Utama, 2009.

Salim, HS. Hukum Kontrak, Perjanjian, Pinjaman, dan Hibah. Cet.1, Jakarta: Sinar Grafika, 2015.

Salim, HS. Hukum Kontrak, Teori \& Teknik Penyusunan Kontrak Cet.1. Jakarta: Sinar Grafika, 2003.

Sanusi, M. Arsyad. E-commerce: Hukum dan Solusinya. Jakarta: Mizan Grafika Sarana, 2007. 


\footnotetext{

} 